OPEN ACCESS

Edited by:

Qian Xiao,

Rutgers Cancer Institute of New Jersey, United States

Reviewed by:

Zhaohui Du,

Fred Hutchinson Cancer Research

Center, United States

Jing Zhang,

University of Texas MD Anderson

Cancer Center, United States

Chen Li,

Freie Universität Berlin, Germany

*Correspondence:

Shen Shen

fccshenk@zzu.edu.cn

${ }^{\dagger}$ These authors have contributed equally to this work

Specialty section:

This article was submitted to

Molecular and Cellular Pathology,

a section of the journal

Frontiers in Cell and Developmental

Biology

Received: 24 July 2021

Accepted: 30 August 2021

Published: 23 September 2021

Citation:

Shen S, Wang Y, Zhang Y, Dong Z and Xing J (2021) Long Non-coding RNA Small Nucleolar RNA Host Gene

14, a Promising Biomarker

and Therapeutic Target in Malignancy.

Front. Cell Dev. Biol. 9:746714.

doi: 10.3389/fcell.2021.746714

\section{Long Non-coding RNA Small Nucleolar RNA Host Gene 14, a Promising Biomarker and Therapeutic Target in Malignancy}

\author{
Shen Shen ${ }^{1,2 * t}$, Yanfang Wang ${ }^{3 t}$, Yize Zhang ${ }^{1,2}$, Zihui Dong ${ }^{1,2}$ and Jiyuan Xing ${ }^{1,2}$ \\ ${ }_{1}^{1}$ Precision Medicine Center, Gene Hospital of Henan Province, The First Affiliated Hospital of Zhengzhou University, \\ Zhengzhou, China, ${ }^{2}$ Department of Infectious Diseases, The First Affiliated Hospital of Zhengzhou University, Zhengzhou, \\ China, ${ }^{3}$ Department of Pharmacy, The First Affiliated Hospital of Zhengzhou University, Zhengzhou, China
}

Small nucleolar RNA host gene 14 (SNHG14) is a long non-coding RNA found to be overexpressed in various types of cancers. Moreover, the expression level of SNHG14 was closely associated with multiple clinicopathological characteristics such as prognosis, tumor differentiation, TNM stage, and lymph node metastasis. Functionally, gain- and loss-of-function of SNHG14 revealed that overexpressed SNHG14 promoted cancer cell viability, invasion, and migration, whereas its downregulation produced the opposite effect. Mechanistically, regulating its target gene expression by sponging distinct miRNAs might be the major mechanism underlying the oncogenic functions of SNHG14. Thus, SNHG14 might be a promising prognostic biomarker and therapeutic target for cancers. In this review, we discuss the expression profile, biological function, and molecular mechanisms of SNHG14 in cancers to provide a molecular basis for the clinical utility of SNHG14 in the future.

Keywords: malignancy, IncRNA, SNHG14, biomarker, prognosis

\section{INTRODUCTION}

Long non-coding RNAs (lncRNAs) are a group of non-protein-coding RNAs longer than 200 nucleotides in length (Chan and Tay, 2018). Growing evidence shows that lncRNAs play vital roles in normal cellular processes through complicated mechanisms (Ørom et al., 2010; Tian et al., 2010). Dysfunction of IncRNAs implicates pathological conditions, especially cancer (Huarte, 2015; Schmitz et al., 2016; Bhan et al., 2017; Yarani et al., 2018; Zhang and Tang, 2018; Simion et al., 2019). Previous studies have determined the biological function of lncRNAs in cellular development and metabolism, including genome rearrangement (Aznaourova et al., 2020), chromatin modification (Han and Chang, 2015), splicing (Romero-Barrios et al., 2018; Corona-Gomez et al., 2020), mRNA decay (Zhu et al., 2013), genetic imprinting (Barlow and Bartolomei, 2014), and translational regulation (Akhade et al., 2017). Emerging lncRNAs are understood to be involved in regulating gene expression at the transcriptional and post-transcriptional levels (Zhang et al., 2019a). Notably, several lncRNAs usually play an oncogenic role or tumor suppressor roles in carcinogenesis and cancer progression by affecting tumor cell differentiation, viability, invasion, migration, apoptosis, and drug resistance (Wang J. et al., 2018; Ghafouri-Fard et al., 2020a,b). 
LncRNA small nucleolar RNA host gene 14 (SNHG14) is a new lncRNA located on chromosome 15q11.2 in humans. It has played an essential role in promoting inflammation microglia activation (Qi et al., 2017; Zhong et al., 2019; Jiang et al., 2021), sepsis-induced acute kidney injury (Shi et al., 2021), and LPSinduced acute kidney injury (Yang et al., 2021). In addition to its function in tumorigenesis and progression, SNHG14 was found to function as a competing endogenous RNA for microRNAs-382-5p (miR-382-5p) to regulate SPIN1 expression in non-small cell lung cancer (Chen et al., 2020). Tang and Yang (2020) reported that SNHG14 binds to miR-656-3p using dualluciferase reporter assay in hepatocellular carcinoma (HCC). Xie et al. (2020) found that SNHG14 promoted pancreatic ductal adenocarcinoma progression by regulating E-cadherin expression by interacting with EZH2. Collectively, the regulatory mechanisms of SNHG14 are highly complicated and unclear.

In this study, we summarize the latest evidence of SNHG14 in human cancers, especially its abnormal expression, biological functions, and molecular mechanisms, and discuss the potential clinical value of SNHG14 as a novel method for cancer diagnosis, prognosis, and treatment.

\section{CLINICAL RELEVANCE OF SMALL NUCLEOLAR RNA HOST GENE 14 IN CANCERS}

Tissue-specific expression patterns indicate that lncRNAs might be served as potential biomarkers and provide a rationale to target them clinically (Statello et al., 2021; Winkle et al., 2021). To explore the role of SNHG14 in cancer, some research groups have studied the expression profile, roles, and clinical significance of SNHG14 in various types of cancers (Table 1). Feng et al. (2021) reported that 37 of 62 of SNHG14 expressions were significantly increased in bladder cancer tissues than in normal control tissues. Another study found this lncRNA was overexpressed in HCC tissues and cell lines (Lin et al., 2021). Up-regulation of SNHG14 in tumor tissues was also found in multiple cancer types, such as NSCLC (Zhang et al., 2019d), HCC (Pu et al., 2019), osteosarcoma (Hou and Mao, 2020), ovarian cancer (Zhao and Huang, 2019), glioma (Lu et al., 2020), prostate cancer (Luo et al., 2020), breast cancer (Dong et al., 2018a), clear cell renal cell carcinoma (Liu et al., 2017), retinoblastoma (Sun et al., 2020), acute myeloid leukemia (Wang et al., 2021a), pancreatic cancer (Zhang et al., 2019b), colorectal cancer (Han et al., 2020), cervical cancer (Ji et al., 2019), and endometrial cancer (Zhao et al., 2020). Notably, the expression of SNHG14 in glioma (Wang Q. et al., 2018), colorectal cancer (Zhang W. et al., 2020), and endometrial carcinoma (Zhang K. et al., 2020) was controversial. We suggest that large sample size and cross-regional or even cross-national multicenter large sample verification may provide better evidence for the conclusion. We believe that the existing studies are contradictory and may be affected by various factors such as detection methods, sensitivity and experimental conditions These seemingly contradictory conclusions suggest that further research is needed to this regard.
Importantly, the expression level of SNHG14 has been demonstrated correlated with prognosis in patients with NSCLC (Zhang et al., 2019d), HCC (Zhang H. et al., 2020), ovarian cancer (Zhao J. L. et al., 2019), retinoblastoma (Sun et al., 2020), pancreatic ductal adenocarcinoma (Xie et al., 2020), colorectal cancer (Pei et al., 2019), cervical cancer (Ji et al., 2019), and endometrial cancer (Zhao et al., 2020). Furthermore, some researchers discovered that highly expressed SNHG14 was positively correlated with large tumor size, advanced TNM stage, distant metastasis and poor tumor differentiation in bladder cancer (Feng et al., 2021), NSCLC (Zhang et al., 2019d), HCC (Liao et al., 2021), prostate cancer (Luo et al., 2020), retinoblastoma (Sun et al., 2020), pancreatic cancer (Deng et al., 2019), and cervical cancer (Ji et al., 2019). The results indicate that SNHG14 can become a prognostic indicator of cancers.

ROC curves analysis showed that the sensitivity of SNHG14 in HCC was $98.5 \%$ and the optimal cutoff value of SNHG14 was 1.22 (Tang and Yang, 2020). In bladder cancer, the survival curve analysis of SNHG14 showed that the area under the curve was 0.842 and the cutoff value was 2.714 , indicating the diagnostic potential of SNHG14 (Li et al., 2019). Zhao et al. (2020) also confirmed the diagnosis efficiency of SNGH14 in ovarian cancer.

Generally, the aforementioned results suggest that SNHG14 plays an oncogenic role in various types of cancer, and it may serve as a new biomarker for cancer diagnosis and prognosis, although further investigation is required for clinical application.

\section{BIOLOGY FUNCTION AND THE MOLECULAR MECHANISM OF SMALL NUCLEOLAR RNA HOST GENE 14 IN VARIOUS CANCERS}

Emerging evidence revealed the expression of SNHG14 in tumor cell lines and the effect of knockdown or overexpression of this lncRNA on tumor cell malignant characteristics such as proliferation, invasion, migration, apoptosis, and drug resistance. The regulatory mechanisms of SNGH14 are complex in distinct types of cancers, even in one cancer. The major mechanism underlying the tumor-promoting function of SNHG14 is to regulate target genes via competing with miRNAs (Table 2). In the following sections, we focus on the function of SNHG14 in various cancers.

\section{Bladder Cancer}

Bladder cancer is one of the most common cancers and has high mortality worldwide (DeGeorge et al., 2017; Lenis et al., 2020). Recently, IncRNAs were found to be closely correlated with bladder occurrence and development (Martens-Uzunova et al., 2014; Cao et al., 2020; Li et al., 2020). However, the molecular mechanism of lncRNAs in the pathogenesis of bladder cancer is still unclear. The expression level of SNHG14 in bladder cancer cell lines (T24, 5637, UMUC-3, and EJ) was higher than in normal bladder epithelial cells SV-HCV-1 (Li et al., 2019; Feng et al., 2021). Feng et al. (2021) reported that knockdown of IncRNA in T24 cells suppressed cell proliferation, migration, 
and invasion, while facilitating cell apoptosis, overexpression this lncRNA shows an opposite effect. The results of bioinformatic analysis and luciferase reporter assay demonstrated that SNHG14 functions as a cancer-promoting gene by targeting miR-211$3 p$ to regulate ESM1 expression (Feng et al., 2021). In other studies, the overexpression of SNHG14 was found to accelerate the proliferative potential by sponging miR-150-5p to degrade VAMP2 expression (Li et al., 2019). The aforementioned results suggest that SNHG14 is a potential therapeutic target for bladder cancer.

\section{Non-small Cell Lung Cancer}

Lung cancer is the most commonly diagnosed cancer, with approximately 1.8 million cancer-related deaths worldwide in 2018 (Bray et al., 2018). NSCLC accounts for 85\% of all lung cancer cases (Ginn et al., 2020). The 5-year survival rate for patients with advanced-stage NSCLC remains approximately $14 \%$ (Ko et al., 2018). This highlights a need to develop new ways to tackle the disease. Zhang et al. (2019d) reported that SNHG14 expression was markedly higher in NSCLC cell lines (including A549, NCI-H1975, NCI-H1299, and SKMES-1) than normal 16HBGE cells, and overexpression of SNHG14 promoted cell proliferation by targeting miR-340. A recent study found that overexpression of SNHG14 facilitates NSCLC cell proliferation, invasion, and migration by regulating G6PD expression by sponging miR-206 (Zhao et al., 2020). Similarly, Chen et al. (2020) demonstrated that SNHG14 accelerated NSCLC progression via the miR-382-5P/SPIN1 axis. Additionally, SNHG14 was reported to influence NSCLC cisplatin resistance by modulating the HMGB1 expression through targeting miR-34a (Jiao et al., 2019). Specifically, in this research, the expression of SNHG14 was remarkably high in cisplatin-resistant NSCLC cell lines (A549 and H1299) compared with that in the human bronchial epithelioid cell line (16HBE). SNHG14 silencing or overexpression miR-34a promoted cell sensitivity to cisplatin (Jiao et al., 2019). SNHG14 was also revealed to regulate the cisplatin resistance through the miR133a/HOXB13 pathway (Xu L. et al., 2020). Wu et al. (2019)

TABLE 1 | Expression of SNHG14 in clinical samples.

\begin{tabular}{|c|c|c|c|c|c|}
\hline Cancer types & $\begin{array}{l}\text { Numbers of } \\
\text { tissues }\end{array}$ & Expression & Clinicopathological characteristics & Prognosis & References \\
\hline \multirow[t]{2}{*}{ Bladder cancer } & 62 pairs & High & $\begin{array}{l}\text { Advanced TNM stage, tumor invasion stage, and lymph node } \\
\text { metastasis }\end{array}$ & Poor & Feng et al., 2021 \\
\hline & 24 pairs & High & Not studied & Poor & Li et al., 2019 \\
\hline \multirow[t]{3}{*}{ Non-small cell lung cancer } & 99 pairs & High & Larger tumor size and advanced TNM stage & Poor & Zhang et al., 2019d \\
\hline & 74 pairs & High & Not studied & Not studied & Zhao et al., 2020 \\
\hline & 50 pairs & High & Not studied & Not studied & Chen et al., 2020 \\
\hline \multirow[t]{3}{*}{ Hepatocellular carcinoma } & 55 pairs & High & Later stage & Not studied & Xu X. et al., 2020 \\
\hline & 40 pairs & High & Not studied & Poor & Zhang H. et al., 2020 \\
\hline & 66 pairs & High & Advanced stage & Poor & Liao et al., 2021 \\
\hline Osteosarcoma & 31 pairs & High & Not studied & Not studied & Hou and Mao, 2020 \\
\hline \multirow[t]{2}{*}{ Ovarian cancer } & 24 pairs & High & Not studied & Poor & Zhao and Huang, 2019 \\
\hline & 56 pairs & High & Not studied & Poor & Zhao J. L. et al., 2019 \\
\hline \multirow[t]{2}{*}{ Glioma } & 8 pairs & High & Not studied & Not studied & Lu et al., 2020 \\
\hline & 29 pairs & Low & Not studied & Not studied & Wang Q. et al., 2018 \\
\hline Breast cancer & 36 pairs & High & Not studied & Not studied & Dong et al., 2018b \\
\hline Retinoblastoma & 43 pairs & High & Advanced stage and differentiation grade & Poor & Sun et al., 2020 \\
\hline \multirow[t]{2}{*}{ Diffuse large B cell lymphoma } & 3 pairs & High & Not studied & Not studied & Zhao L. et al., 2019 \\
\hline & 21 pairs & High & Not studied & Not studied & Tian et al., 2021 \\
\hline Acute myeloid leukemia & 57 pairs & High & Not studied & Not studied & Wang et al., 2021a \\
\hline \multirow[t]{3}{*}{ Pancreatic cancer } & $\begin{array}{c}65 \text { tumor and } \\
30 \text { normal } \\
\text { tissues }\end{array}$ & High & Not studied & Not studied & Zhang et al., 2019b \\
\hline & 45 pairs & High & Poor tumor differentiation, advanced TNM stage, and nodal metastasis & Not studied & Deng et al., 2019 \\
\hline & 58 pairs & High & Advanced TNM stage and positive lymph node metastasis & Poor & Xie et al., 2020 \\
\hline \multirow[t]{4}{*}{ Colorectal cancer } & 92 pairs & Low & Not studied & Poor & Zhang W. et al., 2020 \\
\hline & 50 pairs & High & Not studied & Not studied & Han et al., 2020 \\
\hline & 32 pairs & High & Not studied & Poor & Pei et al., 2019 \\
\hline & 30 pairs & High & Tumor stage, tumor size, and distant metastasis & Not studied & Wang et al., 2021b \\
\hline \multirow[t]{2}{*}{ Cervical cancer } & 80 pairs & High & Advanced FIGO stage, differentiation, and lymph node metastasis & Poor & Ji et al., 2019 \\
\hline & 30 pairs & High & $\begin{array}{l}\text { Large tumor size, later stage and a higher incidence of lymph node } \\
\text { metastasis }\end{array}$ & Poor & Zhang et al., 2019c \\
\hline \multirow[t]{2}{*}{ Endometrial cancer } & 52 pairs & High & Larger tumor size and distance metastasis & Poor & Zhao et al., 2020 \\
\hline & 53 pairs & Low & FIGO stage, histological grade, and lymphatic metastasis & Better & Zhang K. et al., 2020 \\
\hline
\end{tabular}


TABLE 2 | Mechanism underlying the function of SNHG14 in various cancers.

\begin{tabular}{|c|c|c|c|c|c|}
\hline Cancer types & Assessed cell lines & Function & $\begin{array}{l}\text { Molecular } \\
\text { mechanism }\end{array}$ & $\begin{array}{l}\text { Target genes and } \\
\text { related signal pathway }\end{array}$ & References \\
\hline \multirow[t]{2}{*}{$\begin{array}{l}\text { Bladder cancer } \\
\text { (BCa) }\end{array}$} & $\begin{array}{l}\text { BCa cell lines (T24, 5637, UMUC-3, and EJ) and normal bladder } \\
\text { epithelial cells SV-HVC-1 }\end{array}$ & $\begin{array}{l}\text { Invasion, } \\
\text { migration, and } \\
\text { proliferation }\end{array}$ & $\begin{array}{l}\text { Sponging } \\
\text { miR-211-3p }\end{array}$ & ESM1 & Feng et al., 2021 \\
\hline & $\begin{array}{l}\text { Normal bladder transitional epithelial cell line SV-HUC1 and BCa } \\
\text { cell lines T24, UC9, PAL19, and UC19 }\end{array}$ & Proliferation & $\begin{array}{l}\text { Sponging } \\
\text { miR-150-5p }\end{array}$ & VAMP2 & Li et al., 2019 \\
\hline \multirow{6}{*}{$\begin{array}{l}\text { Non-small cell } \\
\text { lung cancer } \\
\text { (NSCLC) }\end{array}$} & $\begin{array}{l}\text { NSCLC cells A549, NCl-H1975, NCl-H1299, SK-MES-1, and } \\
\text { normal human bronchial epithelial 16HBE cells }\end{array}$ & Proliferation & $\begin{array}{l}\text { Sponging } \\
\text { miR-340 }\end{array}$ & Not studied & Zhang et al., 2019d \\
\hline & $\begin{array}{l}\text { Bronchial epithelioid cell line 16HBE and two NSCLC cell lines A549 } \\
\text { and H1299 }\end{array}$ & $\begin{array}{l}\text { Cisplatin } \\
\text { resistance }\end{array}$ & $\begin{array}{l}\text { Sponging } \\
\text { miR-34a }\end{array}$ & HMGB1 & Jiao et al., 2019 \\
\hline & NSCLC cell line PC9, gefitinib-resistant PC9 cell line (PC9/GR) & $\begin{array}{l}\text { Gefitinib } \\
\text { resistance }\end{array}$ & $\begin{array}{l}\text { Sponging } \\
\text { miR-206-3p }\end{array}$ & Not studied & Wu et al., 2019 \\
\hline & $\begin{array}{l}\text { Normal bronchial epithelial 16HBE cells and two NSCLC cell lines } \\
\text { (A549 and SK-MES-1) }\end{array}$ & $\begin{array}{l}\text { Proliferation, } \\
\text { invasion, and } \\
\text { migration }\end{array}$ & $\begin{array}{l}\text { Sponge for } \\
\text { miR-206 }\end{array}$ & Not studied & Zhao et al., 2020 \\
\hline & NSCLC cell (A549) and DDP-resistant NSCLC cell (A549/DDP) & $\begin{array}{l}\text { Cisplatin } \\
\text { resistance }\end{array}$ & $\begin{array}{l}\text { Sponging } \\
\mathrm{miR}-133 \mathrm{a}\end{array}$ & HOXB13 & Xu L. et al., 2020 \\
\hline & $\begin{array}{l}\text { H1299 and A549 cells compared with that in normal lung cell } \\
\text { BEAS-2B }\end{array}$ & $\begin{array}{l}\text { Migration, } \\
\text { invasion, and } \\
\text { apoptosis }\end{array}$ & $\begin{array}{l}\text { Sponging } \\
\text { miR-382-5p }\end{array}$ & SPIN1 & Chen et al., 2020 \\
\hline \multirow{5}{*}{$\begin{array}{l}\text { Hepatocellular } \\
\text { carcinoma } \\
(\mathrm{HCC})\end{array}$} & HCC cell lines (Hep3B and Huh-7) and normal liver cell line L02 & $\begin{array}{l}\text { Proliferation } \\
\text { and apoptosis }\end{array}$ & $\begin{array}{l}\text { Sponging } \\
\text { miR-4673 }\end{array}$ & SOCS1 & Pu et al., 2019 \\
\hline & $\begin{array}{l}\text { Liver epithelial cell line (THLE-2) and the HCC cell line (Huh-7, } \\
\text { Hep3B) }\end{array}$ & $\begin{array}{l}\text { Cell proliferation } \\
\text { and apoptosis }\end{array}$ & $\begin{array}{l}\text { Sponging } \\
\text { miR-217-5p }\end{array}$ & MAPK/ERK signaling & Xu X. et al., 2020 \\
\hline & $\begin{array}{l}\text { HCC cells (HepG2, Hep3B, MHCC-97H, and Huh-7) and human } \\
\text { hepatocyte cells (LO2) }\end{array}$ & $\begin{array}{l}\text { Proliferation, } \\
\text { invasion, and } \\
\text { migration }\end{array}$ & $\begin{array}{l}\text { Sponging } \\
\text { miR-656-3p }\end{array}$ & SIRT5 & $\begin{array}{l}\text { Tang and Yang, } \\
2020\end{array}$ \\
\hline & $\begin{array}{l}\text { Human hepatic cell line L02 cells, human HCC cell lines Hep3B, } \\
\text { SMMC7721, Huh7, HepG2, and MHCC-97H cells }\end{array}$ & $\begin{array}{l}\text { Proliferation, } \\
\text { migration, and } \\
\text { angiogenesis }\end{array}$ & $\begin{array}{l}\text { Regulating } \\
\text { PABPC1 }\end{array}$ & PTEN signaling pathway & $\begin{array}{l}\text { Zhang H. et al., } \\
2020\end{array}$ \\
\hline & $\begin{array}{l}\text { Human hepatic cell line L02 cells and human HCC cell lines HepG2, } \\
\text { Hep3B, HLF, MHCC-97H }\end{array}$ & $\begin{array}{l}\text { Proliferation, } \\
\text { migration, and } \\
\text { invasion }\end{array}$ & $\begin{array}{l}\text { Sponging } \\
\text { miR-876-5p }\end{array}$ & SSR2 & Liao et al., 2021 \\
\hline Osteosarcoma & $\begin{array}{l}\text { 143B, MG-63, Saos-2, HOS, and U2OS cell lines and normal } \\
\text { human osteoblastic cell line (HFOB1.19) }\end{array}$ & $\begin{array}{l}\text { Proliferation, } \\
\text { migration, and } \\
\text { invasion }\end{array}$ & $\begin{array}{l}\text { Sponging } \\
\mathrm{miR}-433-3 p\end{array}$ & $\mathrm{FBXO} 22$ & $\begin{array}{l}\text { Hou and Mao, } \\
2020\end{array}$ \\
\hline \multirow[t]{2}{*}{ Ovarian cancer } & $\begin{array}{l}\text { Normal cell line HOSEpiC and ovarian cancer cell lines including } \\
\text { C13K, SKOV3, 3AO, and OVCAR3 }\end{array}$ & $\begin{array}{l}\text { Proliferation } \\
\text { and cell cycle } \\
\text { progression }\end{array}$ & $\begin{array}{l}\text { Sponging } \\
\text { miR-125a-5p }\end{array}$ & $\mathrm{DH} \times 33$ & $\begin{array}{l}\text { Zhao and Huang, } \\
2019\end{array}$ \\
\hline & $\begin{array}{l}\text { A2780, TO-V112D, HO-8910, OVCAR-3, and SKOV3 and one } \\
\text { normal ovarian cells (ISOE80) }\end{array}$ & $\begin{array}{l}\text { Migration and } \\
\text { invasion }\end{array}$ & $\begin{array}{l}\text { Regulating } \\
\text { DGCR8 }\end{array}$ & DGCR8 & $\begin{array}{l}\text { Zhao J. L. et al., } \\
2019\end{array}$ \\
\hline Glioma & Glioma cell lines U251 and U87 and normal brain glial cell line HEB & $\begin{array}{l}\text { Invasion, and } \\
\text { apoptosis }\end{array}$ & $\begin{array}{l}\text { Sponging } \\
\text { miR-92a-3p }\end{array}$ & Not studied & $\begin{array}{l}\text { Wang Q. et al., } \\
2018\end{array}$ \\
\hline Prostate cancer & $\begin{array}{l}\text { Normal human myofibroblast stromal cell (WPMY1) and human } \\
\text { prostate cancer cell lines, including LNCaP, 22RV1, PC-3, and } \\
\text { DU145 }\end{array}$ & Not studied & $\begin{array}{l}\text { Sponging } \\
\text { miR-5590-3p }\end{array}$ & YY1 & Luo et al., 2020 \\
\hline Breast cancer & Breast cancer cell lines SKBR-3 and BT474 & $\begin{array}{l}\text { Trastuzumab } \\
\text { resistance, } \\
\text { proliferation, } \\
\text { and invasion }\end{array}$ & $\begin{array}{l}\text { Regulating } \\
\text { expression } \\
\text { PABPC1 }\end{array}$ & Not studied & Dong et al., 2018b \\
\hline $\begin{array}{l}\text { Clear cell renal } \\
\text { cell carcinoma } \\
\text { (ccRCC) }\end{array}$ & $\begin{array}{l}\text { Human ccRCC cell lines A-498, } 786-\mathrm{O} \text {, Caki-2, and Caki-1 and } \\
\text { human normal renal epithelial cell line HK-2 }\end{array}$ & $\begin{array}{l}\text { Migration and } \\
\text { invasion }\end{array}$ & $\begin{array}{l}\text { Regulating } \\
\text { N-WASP }\end{array}$ & Not studied & Liu et al., 2017 \\
\hline $\begin{array}{l}\text { Retinoblastoma } \\
\text { (RB) }\end{array}$ & $\begin{array}{l}\text { Three RB cell lines Y79, SO-RB50, and Weri-RB-1 and normal } \\
\text { retinal pigmented epithelial ARPE-19 cell line }\end{array}$ & $\begin{array}{l}\text { Proliferation, } \\
\text { migration and } \\
\text { invasion, and } \\
\text { apoptosis }\end{array}$ & $\begin{array}{l}\text { Sponging } \\
\text { miR-124 }\end{array}$ & STAT3 & Sun et al., 2020 \\
\hline
\end{tabular}


TABLE 2 | (Continued)

\begin{tabular}{|c|c|c|c|c|c|}
\hline Cancer types & Assessed cell lines & Function & $\begin{array}{l}\text { Molecular } \\
\text { mechanism }\end{array}$ & $\begin{array}{l}\text { Target genes and } \\
\text { related signal pathway }\end{array}$ & References \\
\hline \multirow[t]{2}{*}{$\begin{array}{l}\text { Diffuse large B } \\
\text { cell lymphoma }\end{array}$} & $\begin{array}{l}\text { Lymphoblastoid B cell (GM12878), human renal epithelial cell } \\
\text { (293T), murine DLBCL cell (A20), and DLBCL cells (OCI-LY7, DB, } \\
\text { U2932, and FARAGE) }\end{array}$ & $\begin{array}{l}\text { Proliferation, } \\
\text { migration and } \\
\text { epithelial- } \\
\text { mesenchymal } \\
\text { transition }\end{array}$ & $\begin{array}{l}\text { Sponging } \\
\text { miR-5590-3p }\end{array}$ & ZEB1 & Zhao L. et al., 2019 \\
\hline & $\begin{array}{l}\text { Lymphoblastoid B cell (GM12878), germinal center B cell (GCB)-like } \\
\text { cell line (OCI-LY-7), and activated B cell (ABC)-subtype cell line } \\
\text { (OCI-LY-3 and RCK-8) }\end{array}$ & $\begin{array}{l}\text { Proliferation, } \\
\text { apoptosis, and } \\
\text { migration }\end{array}$ & $\begin{array}{l}\text { Sponging } \\
\text { miR-152-3p }\end{array}$ & Not studied & Tian et al., 2021 \\
\hline $\begin{array}{l}\text { Acute myeloid } \\
\text { leukemia (AML) }\end{array}$ & $\begin{array}{l}\text { Human normal bone marrow CD34+ cells and AML cell lines } \\
\text { (MV-4-11, AML-193, HL-60, and KG-1 cells) }\end{array}$ & $\begin{array}{l}\text { Proliferation } \\
\text { and apoptosis }\end{array}$ & $\begin{array}{l}\text { Sponging miR- } \\
\text { 193b-3p/MCL1 }\end{array}$ & Not studied & Wang et al., 2021a \\
\hline \multirow[t]{2}{*}{$\begin{array}{l}\text { Pancreatic } \\
\text { cancer }\end{array}$} & $\begin{array}{l}\text { Pancreatic cancer cell line (SW1990), normal pancreatic cell line } \\
\text { (HPDE6C7), and the human embryonic kidney 293T cell line }\end{array}$ & $\begin{array}{l}\text { Proliferation, } \\
\text { migration, and } \\
\text { invasion }\end{array}$ & $\begin{array}{l}\text { Sponging } \\
\text { miR-101 }\end{array}$ & Not studied & Zhang et al., 2019b \\
\hline & $\begin{array}{l}\text { Normal immortalized human pancreatic epithelial cell line } \\
\text { (HPDE6C7) and four human pancreatic cancer cell lines (CFPAC-1, } \\
\text { BXPC3, L3.6pl, and Panc-1) }\end{array}$ & $\begin{array}{l}\text { Proliferative, } \\
\text { invasive } \\
\text { potentials, and } \\
\text { apoptosis }\end{array}$ & $\begin{array}{l}\text { Sponging } \\
\text { miR-613 }\end{array}$ & Annexin A2 & Deng et al., 2019 \\
\hline $\begin{array}{l}\text { Pancreatic ductal } \\
\text { adenocarcinoma }\end{array}$ & $\begin{array}{l}\text { Panc1, Panc28, AsPC1, and BxPC3 and a human pancreatic } \\
\text { ductal epithelial cell line HPDE }\end{array}$ & $\begin{array}{l}\text { Proliferation } \\
\text { and invasion } \\
\text { ability }\end{array}$ & $\begin{array}{l}\text { Interacting with } \\
\mathrm{EZH} 2\end{array}$ & Not studied & Xie et al., 2020 \\
\hline \multirow[t]{7}{*}{$\begin{array}{l}\text { Colorectal } \\
\text { cancer (CRC) }\end{array}$} & $\begin{array}{l}\text { Normal human colorectal cell line NCM460 and five CRC cell lines } \\
\text { (LoVo, SW620, SW480, HCT116, and HT-29) }\end{array}$ & $\begin{array}{l}\text { Proliferation, } \\
\text { motility, and } \\
\text { epithelial- } \\
\text { mesenchymal } \\
\text { transition }\end{array}$ & $\begin{array}{l}\text { Interacting with } \\
\mathrm{EZH} 2\end{array}$ & EPHA7 & Di et al., 2019 \\
\hline & $\begin{array}{l}\text { Normal human colon epithelial cells (FHC) and other five human } \\
\text { CRC cancer cells (Caco-2, HT-29, HCT-116, SW480, a nd SW62) }\end{array}$ & $\begin{array}{l}\text { Cell growth, } \\
\text { migration, } \\
\text { invasion, and } \\
\text { apoptosis }\end{array}$ & $\begin{array}{l}\text { Sponging } \\
\text { miR-92b-3p }\end{array}$ & Not studied & $\begin{array}{l}\text { Zhang W. et al., } \\
2020\end{array}$ \\
\hline & $\begin{array}{l}\text { CRC cell lines (SW620 and SW480), a normal human colon } \\
\text { mucosal epithelial cell line (NCM460), and the human embryonic } \\
\text { kidney (HEK) } 293 \text { T cell line }\end{array}$ & $\begin{array}{l}\text { Cisplatin } \\
\text { resistance, } \\
\text { proliferation, } \\
\text { migration, and } \\
\text { invasion }\end{array}$ & $\begin{array}{l}\text { Sponging } \\
\text { miR-186 }\end{array}$ & ATG14 & Han et al., 2020 \\
\hline & $\begin{array}{l}\text { CRC cell lines SW620, HCT116 cells, and human normal epithelial } \\
\text { colonic cells NCM460 }\end{array}$ & $\begin{array}{l}\text { Proliferation, } \\
\text { migration, } \\
\text { invasion, and } \\
\text { apoptosis }\end{array}$ & $\begin{array}{l}\text { Sponging } \\
\text { miR-944 }\end{array}$ & KRAS/PI3K/AKT pathway & Pei et al., 2019 \\
\hline & $\begin{array}{l}\text { CRC cell lines (LoVo, RKO, SW480, and HT-29) and normal colon } \\
\text { epithelial cells (NCM460) }\end{array}$ & $\begin{array}{l}\text { Proliferation, } \\
\text { metastasis, and } \\
\text { epithelial- } \\
\text { mesenchymal } \\
\text { transition } \\
\text { process }\end{array}$ & $\begin{array}{l}\text { Sponging } \\
\text { miR-32-5p }\end{array}$ & SKIL & Ye et al., 2019 \\
\hline & & & $\begin{array}{l}\text { Sponging } \\
\text { miR-519b-3p }\end{array}$ & DDX5 & Wang et al., 2021b \\
\hline & $\begin{array}{l}\text { Human CRC cell lines (SW480, HT-29, HCT-8 and DLD-1) and } \\
\text { human normal colon epithelial cells (NCM460) }\end{array}$ & $\begin{array}{l}\text { Proliferation, } \\
\text { migration, } \\
\text { invasion, and } \\
\text { apoptosis }\end{array}$ & & & \\
\hline \multirow[t]{2}{*}{$\begin{array}{l}\text { Cervical cancer } \\
\text { (CC) }\end{array}$} & $\begin{array}{l}\text { CC cell lines (SiHa, HeLa, C33a, Me180, and Ms751) and human } \\
\text { normal cervical cell lines (Ect1/E6E7) }\end{array}$ & $\begin{array}{l}\text { Proliferation, } \\
\text { migration, } \\
\text { invasion, and } \\
\text { apoptosis }\end{array}$ & $\begin{array}{l}\text { Sponging } \\
\text { miR-206 }\end{array}$ & YWHAZ & Ji et al., 2019 \\
\hline & $\begin{array}{l}\text { CC cell lines (SW756, SiHa, and HeLa) and normal endo-cervical } \\
\text { epithelial cell line (End1/E6E7) }\end{array}$ & $\begin{array}{l}\text { Proliferation } \\
\text { and apoptosis }\end{array}$ & & JAK-STAT pathway & Zhang et al., 2019c \\
\hline \multirow[t]{2}{*}{$\begin{array}{l}\text { Endometrial } \\
\text { cancer (EC) }\end{array}$} & $\begin{array}{l}\text { Human EC cell lines (HEC-1A, HEC-1B, KLE, and Ishikawa) and } \\
\text { human endometrial stromal cell line (T-HESC) }\end{array}$ & $\begin{array}{l}\text { Cell proliferation } \\
\text { and apoptosis }\end{array}$ & $\begin{array}{l}\text { Sponging } \\
\text { miR-655-3P }\end{array}$ & Not studied & Zhao et al., 2020 \\
\hline & $\begin{array}{l}\text { Human embryonic stem cell and EC cell lines (HEC1-A, HEC1-B, } \\
\text { AN3CA, and Ishikawa) }\end{array}$ & $\begin{array}{l}\text { Viability, } \\
\text { migration, and } \\
\text { invasion }\end{array}$ & $\begin{array}{l}\text { Sponging } \\
\text { miR-93-5p }\end{array}$ & Not studied & $\begin{array}{l}\text { Zhang K. et al., } \\
2020\end{array}$ \\
\hline
\end{tabular}




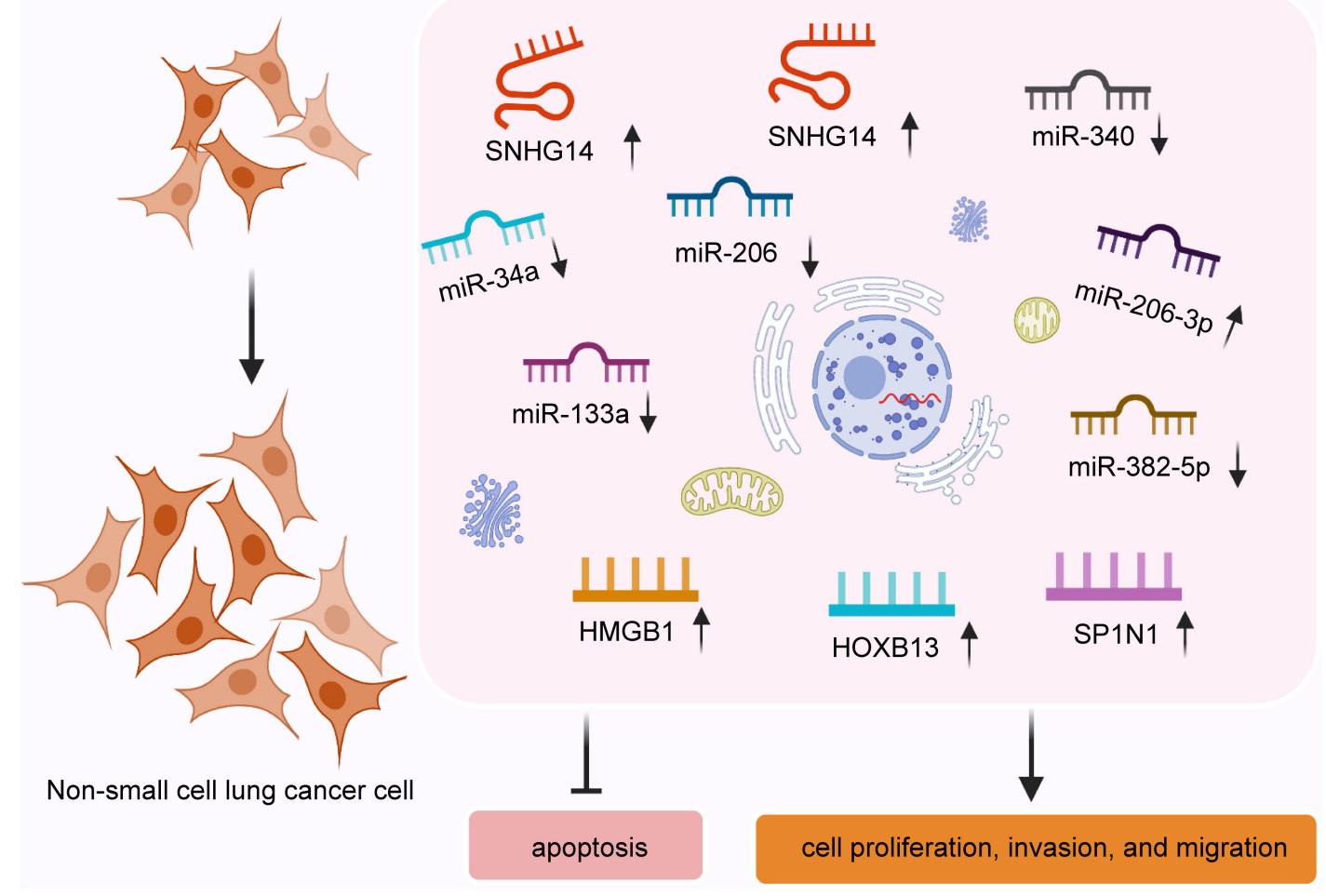

FIGURE 1 | SNHG14 enhances non-small cell lung cancer cell proliferation, invasion, and migration and inhibits cell apoptosis by regulating target genes through sponging miRNAs.

found that SNHG14 expression was increased in gefitinibresistant cells, and overexpression of SNGH14 promoted gefitinib resistance by facilitating cell growth and restraining cell apoptosis through interacting with miR-206-3P.

Briefly, SNHG14 plays a vital role in promoting NSCLC cell proliferation, migration, invasion, and chemoresistance and inhibiting cell apoptosis by regulating targets by sponging different miRNAs (Figure 1). SNHG14 is expected to provide a novel strategy for NSCLC treatment.

\section{Hepatocellular Carcinoma}

HCC is one of the most commonly diagnosed cancers and ranks the fourth leading cause of cancer-related deaths worldwide in 2018 (Bray et al., 2018). Dysregulated lncRNAs have been found closely related to tumorigenesis, prognosis, and diagnosis (Abbastabar et al., 2018; Wong et al., 2018; Pan et al., 2019). SNHG14 was found highly expressed in HCC cell lines compared with that in the normal cell line. As for biological function, the overexpression of this lncRNA accelerated cell proliferation, invasion, and migration and suppressed cell apoptosis. Conversely, knockdown of SNHG14 could cause the exact opposite effects on HCC cells (Pu et al., 2019; Tang and Yang, 2020; Xu X. et al., 2020; Zhang H. et al., 2020; Liao et al., 2021). Mechanistic investigations demonstrated that SNHG14 functions as a competing endogenous RNA and sponged miRNAs, such as miR4673, miR-217-5p, miR-656-3p, and miR-876-5p (Pu et al., 2019;
Tang and Yang, 2020; Zhang H. et al., 2020; Liao et al., 2021). Thus, activating downstream gene expression, such as, SOCS1, SIRT5, and SSR2 (Figure 2; Pu et al., 2019; Tang and Yang, 2020; Liao et al., 2021). Another research group reported that SNHG14 contributed to tumor cell malignant cells by increasing poly(A) binding protein cytoplasmic 1 (PABPC1) expression through H3K27 acetylation. In this study, gain- and loss-offunction experiments also revealed that the phosphatase and tensin homolog (PTEN) signaling pathway was involved in SNHG14/PABPC1-mediated regulation of tumorigenesis in vitro and in vivo (Figure 2; Zhang $\mathrm{H}$. et al., 2020). Accordingly, SNHG14 has an oncogenic role and might be a potential therapeutic target in HCC.

\section{Ovarian Cancer}

The SNHG14 expression level was enormously high in ovarian cancer cells compared with the control cell line (Zhao J. L. et al., 2019; Zhao and Huang, 2019). Zhao et al. discovered that overexpressed SNHG14 could accelerate cell proliferation and cell cycle. Dual-luciferase assay indicated that SNHG14 could directly bind to miR-125a-5p, and overexpression of miR-125a5 p reversed the effect of promoting tumor of SNHG14 on ovarian cancer cells (Zhao and Huang, 2019). SNHG14 was also found to promote ovarian cancer metastasis by regulating DGCR8 expression (Zhao J. L. et al., 2019). Although the underlying molecular mechanism and signaling pathway need to be further 


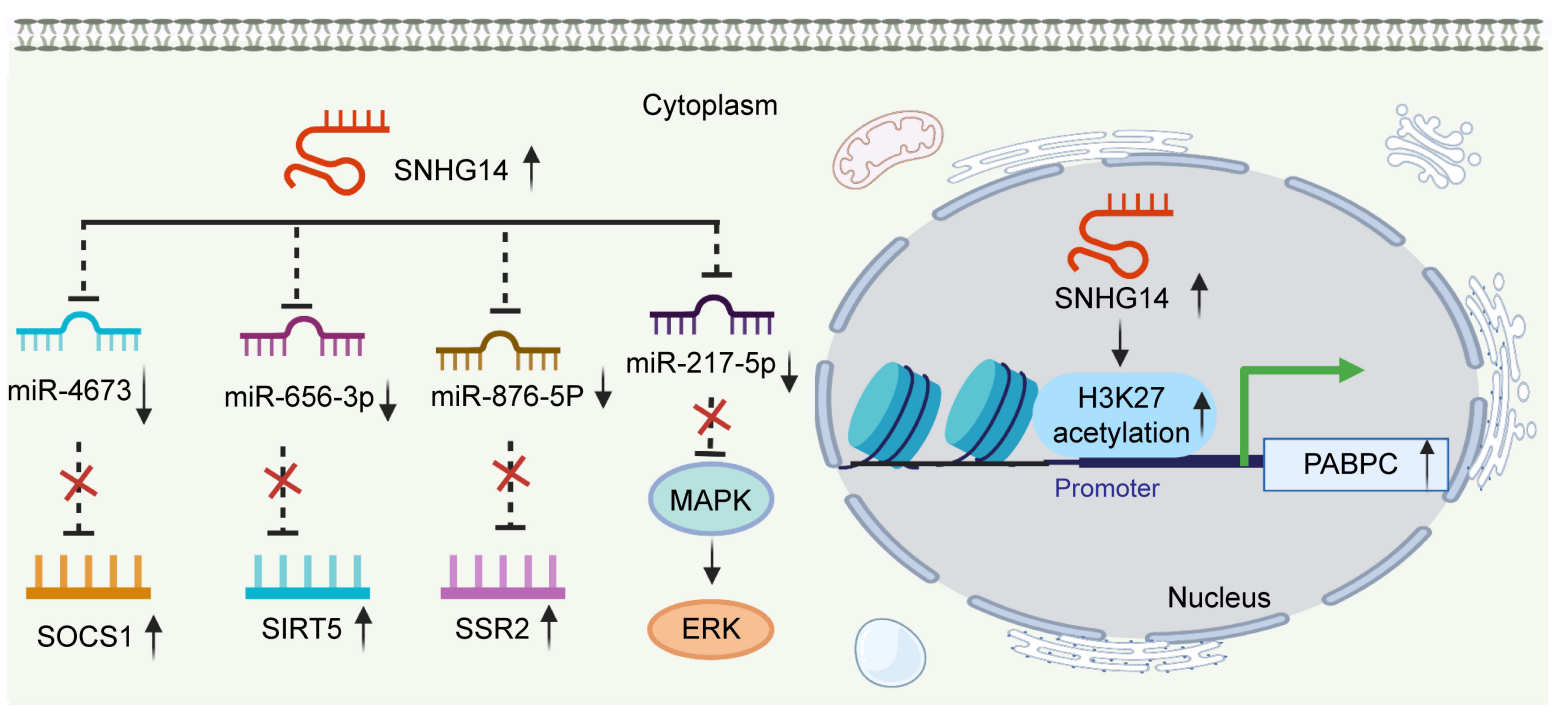

FIGURE 2 | SNHG14 mediates mechanisms involved in HCC.

studied, the aforementioned evidence proved novel clues for the treatment of ovarian cancer.

\section{Breast Cancer}

Breast cancer with overexpression of human epidermal growth factor receptor 2 (HER2) accounted for 20-30\% of all breast cancers and had poorer prognosis ( $\mathrm{Vu}$ and Claret, 2012; Robidoux et al., 2013). Trastuzumab is an HER2 inhibitor that is used for initial and advanced treatment. However, trastuzumab resistance has been a significant obstacle to improving the outcome of patients (Wolff et al., 2007; Narayan et al., 2009). To explore the contributions of lncRNAs in trastuzumab resistance and progression of breast cancer, Dong et al. (2018b) cultured human breast cancer cell lines SKBR-3 and BT474 and trastuzumab-resistant SKBR$3 / \mathrm{Tr}$ and BT474/Tr cells to identify the role of SNHG14 in breast cancer progression and drug resistance. Functional experimentation demonstrated that knockdown of SNHG14 restrain cell proliferation, invasion, trastuzumab resistance, and the overexpression of SNHG14 abolished this effect. Consistent with this effect, Dong et al. (2018a) also found SNHG14 promoted trastuzumab chemoresistance in breast cancer. Thus, SNHG14 may serve as a promising target for patients with HER2positive breast cancer.

\section{Colorectal Cancer}

In colorectal cancer, Di et al. (2019) found that the level of SNHG14 was markedly upregulated in colorectal cancer cell lines compared with that in the control colonic cell line (Wang et al., 2021b). Overexpression of SNHG14 promoted colorectal cancer cell proliferation, invasion, and migration and epithelialmesenchymal transition in vitro and enhanced tumor growth and distant metastasis in vivo (Di et al., 2019; Pei et al., 2019; Ye et al., 2019; Han et al., 2020). Furthermore, mechanistic investigations demonstrated that SNHG14 facilitates colorectal cancer progression by targeting EZH2-regulated EPHA7 and absorbing miR-186-5p (Di et al., 2019). Pei et al. (2019) reported that SNHG14 could serve as an oncogene by regulating the miR944/KRAS axis via the PI3K/AKT signaling pathway. SNHG14 was also found to regulate colorectal cancer progression via the miR-32-5p/SKIL and miR-186/ATG14 axes (Ye et al., 2019; Han et al., 2020). In contrast to the aforementioned study, a single study reported that SNHG14 was significantly down-regulated in colorectal cancer cell lines compared with that in a normal cell line and SNHG14 exerts an anti-tumor effect through sponging miR-92b-3p (Zhang W. et al., 2020). Thus, further studies are still needed before determining conclusions related to the function and regulatory mechanisms of SNHG14 in colorectal cancer.

\section{Glioma}

Lu et al. (2020) revealed that SNHG14 is involved in reprogramming glucose metabolism and tumorigenesis by interacting with RNA-binding protein Lin28A in glioma. Silencing SNHG14 inhibited glioma cell glycolysis and proliferation while enhancing apoptosis. In contrast to the aforementioned study, another study demonstrated the role of SNHG144 in the suppression of cell proliferation and invasion and promotion of apoptosis in glioma (Wang Q. et al., 2018).

\section{Pancreatic Cancer}

Pancreatic cancer a highly fatal gastrointestinal malignancy and ranks the seventh leading cause of cancer-related deaths (Luchini et al., 2016). Although the diagnosis and management of pancreatic cancer are improved, the 5-year survival rate is as low as 4\% (Vincent et al., 2011; Gandhi et al., 2018). Pancreatic ductal adenocarcinoma is the most common pathological type of pancreatic cancer and lacks effective treatment (Luchini et al., 2016; Gallmeier and Gress, 2018). In recent years, growing amount of evidence shows that lncRNAs may play vital roles in the development and maintenance of pancreatic cancer 


\section{Cytoplasm}
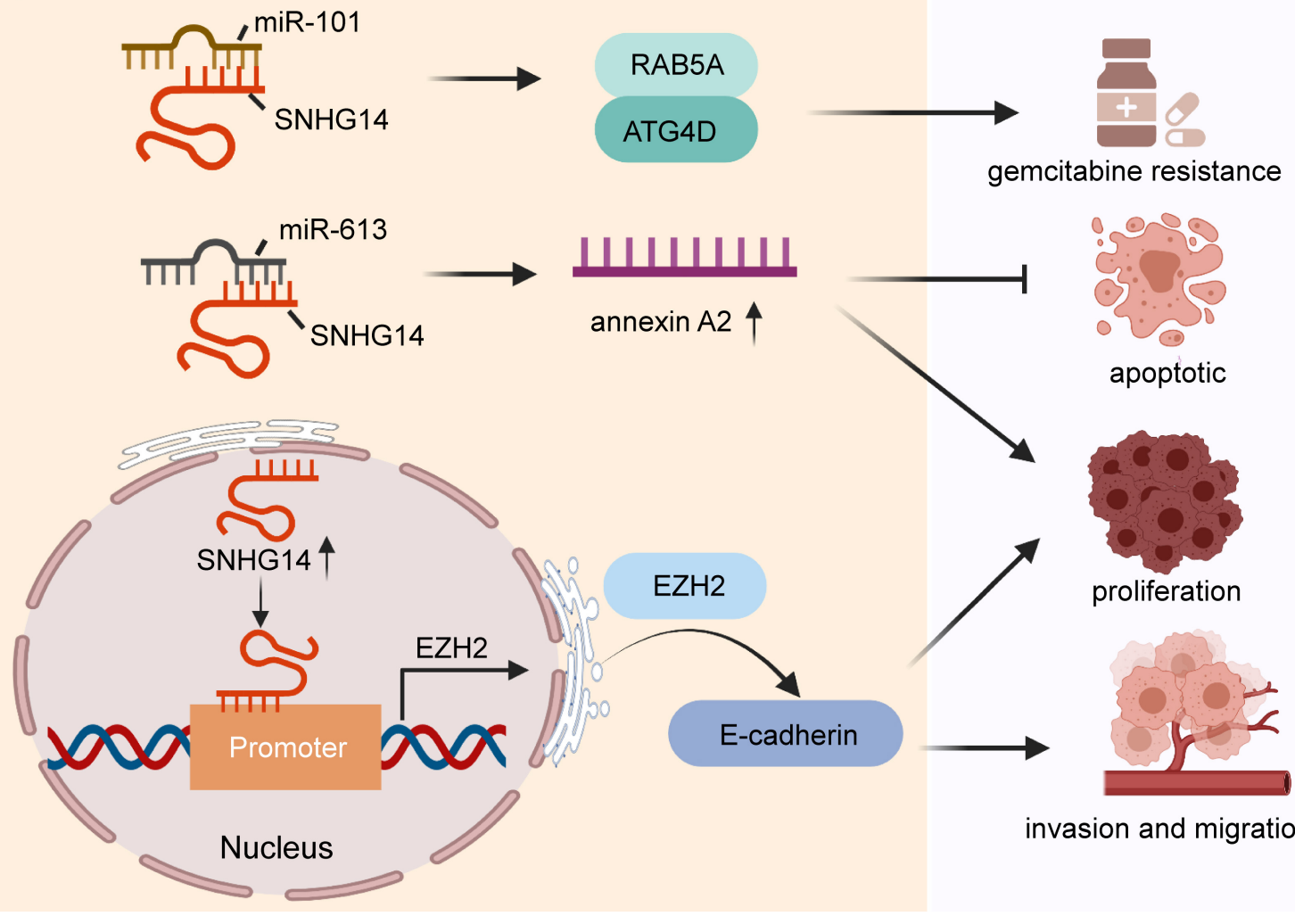

\section{EH2}

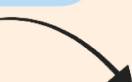

\section{E-cadherin}

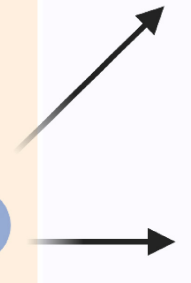

proliferation
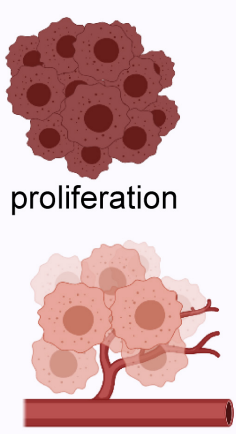

invasion and migration

FIGURE 3 | Function and molecular mechanism of SNHG14 in pancreatic cancer.

(Taucher et al., 2016; Moschovis et al., 2017; Wang J. et al., 2020). Some studies have reported that SNHG14 expression was significantly higher in pancreatic cancer cells compared with that in normal cell lines, and upregulated this lncRNA enhanced cell proliferation and invasion through regulating E-cadherin expression via binding on promoters of EZH2 (Xie et al., 2020). Mechanistically, this lncRNA was also found to potentiate tumor progression through modulation of target gene annexin A2 via sponging miR-613 (Deng et al., 2019). Alternatively, Zhang et al. (2019b) reported that SNHG14 increased gemcitabine resistance to pancreatic cancer cells by increasing autophagy-related proteins (such as RAB5A and ATG4D) through interacting with miR-101. The function and molecular mechanism of SNHG14 are shown in Figure 3. Collectively, SNHG14 shows its role in the initiation, progression, and drug resistance, suggesting its potential role in tumor treatment of pancreatic cancer.

\section{Others}

Other studies on cervical cancer (Ji et al., 2019; Zhang et al., 2019c), prostate cancer (Luo et al., 2020), osteosarcoma (Hou and Mao, 2020), endometrial cancer (Zhao et al., 2020), retinoblastoma (Sun et al., 2020), clear cell renal cell carcinoma (Liu et al., 2017), diffuse large B cell lymphoma (Zhao L. et al., 2019; Tian et al., 2021), and acute myeloid leukemia (Wang et al., 2021a) indicated a tumor promoter role for SNHG14 through complex molecular mechanisms. Table 2 summarizes the current results of the function, target genes, and signaling pathways in various malignancies.

\section{CONCLUSION AND PERSPECTIVES}

With the development of RNA-seq technologies, bulk lncRNAs are being identified and characterized (Jathar et al., 2017; Wang J. et al., 2018; Qian et al., 2019; Gu et al., 2021). Dysregulation in the expression of lncRNAs has been demonstrated to participate in diverse diseases, especially cancer (Poliseno et al., 2015; Peng and Croce, 2016; Kristensen et al., 2018). LncRNA SNHG14 has been found to be overexpressed in various cancer tissues and is closely associated with multiple clinicopathological characteristics such as prognosis, tumor differentiation, TNM stage, and lymph node metastasis. As a tumor promotion gene, the results of functional experiments have demonstrated that overexpression of this lncRNA could promote tumor cell proliferation, migration, invasion, and chemoresistance and inhibit cell apoptosis. The regulatory mechanism of SNHG14 is complex in distinct types of cancers. To regulate target genes via competing with miRNAs is the major mechanism underlying the tumor-promoting function of SNHG14 by regulating target genes via sponging different miRNAs, such as miR-5590-3p, miR-152-3p, miR-193b-3p, miR92b-3p, miR-186, miR-32, and miR-93-5p (Table 2). 
As for clinical application, high expression of SNHG14 was closely correlated with poorer clinicopathological characteristics; thus, it may be served as a potential biomarker for diagnosis and prognosis. However, most of the studies lack a sufficiently large sample and might have artificial errors. The expression of SNHG14 was tested only in tissues. The expression level of SNHG14 in serum or other biological samples remains unclear and is worth investigating. Therefore, exploring the expression of SNHG14 in blood and other fluids would be beneficial to its clinical application as a diagnostic marker in the future. Additionally, although several studies have addressed the promising role of SNHG14 as a target for cancer treatment, research on SNHG14 is still in its early stages. When could targeting SNHG14 be used in clinical treatment? The main determinant is the availability of drugs (whether oligonucleotide or small molecule drugs) that manipulate SNHG14 activity and deliver them effectively to tumor cells with lasting effects. Furthermore, clarification of the functions and mechanisms

\section{REFERENCES}

Abbastabar, M., Sarfi, M., Golestani, A., and Khalili, E. (2018). LncRNA involvement in hepatocellular carcinoma metastasis and prognosis. EXCLI J. 17, 900-913. doi: 10.17179/excli2018-1541

Akhade, V. S., Pal, D., and Kanduri, C. (2017). Long noncoding RNA: genome organization and mechanism of action. Adv. Exp. Med. Biol. 1008, 47-74. doi: 10.1007/978-981-10-5203-3_2

Aznaourova, M., Schmerer, N., Schmeck, B., and Schulte, L. N. (2020). Diseasecausing mutations and rearrangements in long non-coding RNA gene loci. Front. Genet. 11:527484. doi: 10.3389/fgene.2020.527484

Barlow, D. P., and Bartolomei, M. S. (2014). Genomic imprinting in mammals. Cold Spring Harb. Perspect. Biol. 6:a018382. doi: 10.1101/cshperspect.a018382

Bhan, A., Soleimani, M., and Mandal, S. S. (2017). Long noncoding RNA and cancer: a new paradigm. Cancer Res. 77, 3965-3981. doi: 10.1158/0008-5472. Can-16-2634

Bray, F., Ferlay, J., Soerjomataram, I., Siegel, R. L., Torre, L. A., and Jemal, A. (2018). Global cancer statistics 2018: globocan estimates of incidence and mortality worldwide for 36 cancers in 185 countries. CA Cancer J. Clin. 68, 394-424. doi: 10.3322/caac. 21492

Cao, Y., Tian, T., Li, W., Xu, H., Zhan, C., Wu, X., et al. (2020). Long non-coding RNA in bladder cancer. Clin. Chim. Acta 503, 113-121. doi: 10.1016/j.cca.2020. 01.008

Chan, J. J., and Tay, Y. (2018). Noncoding RNA:RNA regulatory networks in cancer. Int. J. Mol. Sci. 19:1310. doi: 10.3390/ijms19051310

Chen, X., Song, P., Yao, Y., and Yang, Y. (2020). Long non-coding rna snhg14 regulates spin1 expression to accelerate tumor progression in non-small cell lung cancer by sponging mir-382-5p. Cancer Manag. Res. 12, 9113-9123. doi: $10.2147 / \mathrm{cmar}$.S250893

Corona-Gomez, J. A., Garcia-Lopez, I. J., Stadler, P. F., and Fernandez-Valverde, S. L. (2020). Splicing conservation signals in plant long noncoding RNAs. RNA 26, 784-793. doi: 10.1261/rna.074393.119

DeGeorge, K. C., Holt, H. R., and Hodges, S. C. (2017). Bladder cancer: diagnosis and treatment. Am. Fam. Phys. 96, 507-514.

Deng, P. C., Chen, W. B., Cai, H. H., An, Y., Wu, X. Q., Chen, X. M., et al. (2019). LncRNA snhg14 potentiates pancreatic cancer progression via modulation of annexin a2 expression by acting as a competing endogenous RNA for mir-613. J. Cell. Mol. Med. 23, 7222-7232. doi: 10.1111/jcmm.14467

Di, W., Weinan, X., Xin, L., Zhiwei, Y., Xinyue, G., Jinxue, T., et al. (2019). Long noncoding RNA snhg14 facilitates colorectal cancer metastasis through targeting ezh2-regulated epha7. Cell Death Dis. 10:514. doi: 10.1038/s41419019-1707-x of SNHG14 under physiological and pathological conditions is also necessary.

\section{AUTHOR CONTRIBUTIONS}

SS and YW wrote and reviewed the manuscript. YZ collected the references. ZD and JX reviewed the manuscript. All authors contributed to the writing and revision of the manuscript, knew the content of it, and approved its submission.

\section{FUNDING}

This work was supported by the Science and Technology Research Project of Henan Province (202102310115) and the Henan Medical Science and Technology Joint Building Program (LHGJ20200387).

Dong, H., Wang, W., Chen, R., Zhang, Y., Zou, K., Ye, M., et al. (2018a). Exosomemediated transfer of lncRNA-snhg14 promotes trastuzumab chemoresistance in breast cancer. Int. J. Oncol. 53, 1013-1026. doi: 10.3892/ijo.2018.4467

Dong, H., Wang, W., Mo, S., Liu, Q., Chen, X., Chen, R., et al. (2018b). Long non-coding RNA snhg14 induces trastuzumab resistance of breast cancer via regulating pabpc1 expression through h3k27 acetylation. J. Cell. Mol. Med. 22, 4935-4947. doi: 10.1111/jcmm.13758

Feng, R., Li, Z., Wang, X., Ge, G., Jia, Y., Wu, D., et al. (2021). Silenced IncRNA snhg14 restrains the biological behaviors of bladder cancer cells via regulating microrna-211-3p/esm1 axis. Cancer Cell Int. 21:67. doi: 10.1186/s12935-02001717-7

Gallmeier, E., and Gress, T. M. (2018). [pancreatic ductal adenocarcinoma]. Internist 59, 805-822. doi: 10.1007/s00108-018-0460- Z

Gandhi, N. S., Feldman, M. K., Le, O., and Morris-Stiff, G. (2018). Imaging mimics of pancreatic ductal adenocarcinoma. Abdom. Radiol. 43, 273-284. doi: 10. 1007/s00261-017-1330-1

Ghafouri-Fard, S., Dashti, S., Taheri, M., and Omrani, M. D. (2020a). Tincr: an lncRNA with dual functions in the carcinogenesis process. Noncoding RNA Res. 5, 109-115. doi: 10.1016/j.ncrna.2020.06.003

Ghafouri-Fard, S., Omrani, M. D., and Taheri, M. (2020b). Long noncoding RNA pvt1: a highly dysregulated gene in malignancy. J. Cell. Physiol. 235, 818-835. doi: 10.1002/jcp.29060

Ginn, L., Shi, L., Montagna, M., and Garofalo, M. (2020). LncRNAs in non-smallcell lung cancer. Noncoding RNA 6:25. doi: 10.3390/ncrna6030025

Gu, X., Chu, Q., Zheng, Q., Wang, J., and Zhu, H. (2021). The dual functions of the long noncoding RNA casc15 in malignancy. Biomed. Pharmacother. 135:111212. doi: 10.1016/j.biopha.2020.111212

Han, P., and Chang, C. P. (2015). Long non-coding RNA and chromatin remodeling. RNA Biol. 12, 1094-1098. doi: 10.1080/15476286.2015.106 3770

Han, Y., Zhou, S., Wang, X., Mao, E., and Huang, L. (2020). Snhg14 stimulates cell autophagy to facilitate cisplatin resistance of colorectal cancer by regulating mir-186/atg14 axis. Biomed. Pharmacother. 121:109580. doi: 10.1016/j.biopha. 2019.109580

Hou, X. K., and Mao, J. S. (2020). Long noncoding RNA snhg14 promotes osteosarcoma progression via mir-433-3p/fbxo22 axis. Biochem. Biophys. Res. Commun. 523, 766-772. doi: 10.1016/j.bbrc.2020.01.016

Huarte, M. (2015). The emerging role of lncRNAs in cancer. Nat. Med. 21, 1253-1261. doi: 10.1038/nm.3981

Jathar, S., Kumar, V., Srivastava, J., and Tripathi, V. (2017). Technological developments in lncRNA biology. Adv. Exp. Med. Biol. 1008, 283-323. doi: 10.1007/978-981-10-5203-3_10 
Ji, N., Wang, Y., Bao, G., Yan, J., and Ji, S. (2019). LncRNA snhg14 promotes the progression of cervical cancer by regulating mir-206/ywhaz. Pathol. Res. Pract. 215, 668-675. doi: 10.1016/j.prp.2018.12.026

Jiang, H., Ni, J., Zheng, Y., and Xu, Y. (2021). Knockdown of IncRNA snhg14 alleviates lps-induced inflammation and apoptosis of pc12 cells by regulating mir-181b-5p. Exp. Ther. Med. 21:497. doi: 10.3892/etm.2021. 9928

Jiao, P., Hou, J., Yao, M., Wu, J., and Ren, G. (2019). Snhg14 silencing suppresses the progression and promotes cisplatin sensitivity in non-small cell lung cancer. Biomed. Pharmacother. 117:109164. doi: 10.1016/j.biopha.2019.10 9164

Ko, E. C., Raben, D., and Formenti, S. C. (2018). The integration of radiotherapy with immunotherapy for the treatment of non-small cell lung cancer. Clin. Cancer Res. 24, 5792-5806. doi: 10.1158/1078-0432.Ccr-17-3620

Kristensen, L. S., Hansen, T. B., Venø, M. T., and Kjems, J. (2018). Circular RNAs in cancer: opportunities and challenges in the field. Oncogene 37, 555-565. doi: $10.1038 /$ onc.2017.361

Lenis, A. T., Lec, P. M., Chamie, K., and Mshs, M. D. (2020). Bladder cancer: a review. JAMA 324, 1980-1991. doi: 10.1001/jama.2020.17598

Li, J., Wang, A. S., Wang, S., Wang, C. Y., Xue, S., Guan, H., et al. (2019). Lncsnhg14 promotes the development and progression of bladder cancer by targeting mirna-150-5p. Eur. Rev. Med. Pharmacol. Sci. 23, 1022-1029. doi: 10.26355/eurrev_201902_16989

Li, Y., Li, G., Guo, X., Yao, H., Wang, G., and Li, C. (2020). Non-coding RNA in bladder cancer. Cancer Lett. 485, 38-44. doi: 10.1016/j.canlet.2020.04.023

Liao, Z., Zhang, H., Su, C., Liu, F., Liu, Y., Song, J., et al. (2021). Long noncoding RNA snhg14 promotes hepatocellular carcinoma progression by regulating mir876-5p/ssr2 axis. J. Exp. Clin. Cancer Res. 40:36. doi: 10.1186/s13046-02101838-5

Lin, R. X., Zhan, G. F., Wu, J. C., Fang, H., and Yang, S. L. (2021). LncRNA snhg14 sponges mir-206 to affect proliferation, apoptosis, and metastasis of hepatocellular carcinoma cells by regulating sox9. Dig. Dis. Sci. doi: 10.1007/ s10620-021-06920-8 [Epub ahead of print].

Liu, G., Ye, Z., Zhao, X., and Ji, Z. (2017). Sp1-induced up-regulation of IncRNA snhg14 as a ceRNA promotes migration and invasion of clear cell renal cell carcinoma by regulating n-wasp. Am. J. Cancer Res. 7, 2515-2525.

Lu, J., Liu, X., Zheng, J., Song, J., Liu, Y., Ruan, X., et al. (2020). Lin28a promotes irf6-regulated aerobic glycolysis in glioma cells by stabilizing snhg14. Cell Death Dis. 11:447. doi: 10.1038/s41419-020-2650-6

Luchini, C., Capelli, P., and Scarpa, A. (2016). Pancreatic ductal adenocarcinoma and its variants. Surg. Pathol. Clin. 9, 547-560. doi: 10.1016/j.path.2016.05.003

Luo, Z. F., Peng, Y., Liu, F. H., Ma, J. S., Hu, G., Lai, S. L., et al. (2020). Long noncoding RNA snhg14 promotes malignancy of prostate cancer by regulating with mir-5590-3p/yyl axis. Eur. Rev. Med. Pharmacol. Sci. 24, 4697-4709. doi: 10.26355/eurrev_202005_21158

Martens-Uzunova, E. S., Böttcher, R., Croce, C. M., Jenster, G., Visakorpi, T., and Calin, G. A. (2014). Long noncoding RNA in prostate, bladder, and kidney cancer. Eur. Urol. 65, 1140-1151. doi: 10.1016/j.eururo.2013.12.003

Moschovis, D., Gazouli, M., Tzouvala, M., Vezakis, A., and Karamanolis, G. (2017). Long non-coding RNA in pancreatic adenocarcinoma and pancreatic neuroendocrine tumors. Ann. Gastroenterol. 30, 622-628. doi: 10.20524/aog. 2017.0185

Narayan, M., Wilken, J. A., Harris, L. N., Baron, A. T., Kimbler, K. D., and Maihle, N. J. (2009). Trastuzumab-induced her reprogramming in "resistant" breast carcinoma cells. Cancer Res. 69, 2191-2194. doi: 10.1158/0008-5472.Can-081056

Ørom, U. A., Derrien, T., Beringer, M., Gumireddy, K., Gardini, A., Bussotti, G., et al. (2010). Long noncoding RNAs with enhancer-like function in human cells. Cell 143, 46-58. doi: 10.1016/j.cell.2010.09.001

Pan, W., Li, W., Zhao, J., Huang, Z., Zhao, J., Chen, S., et al. (2019). LncRNA-pdpk2p promotes hepatocellular carcinoma progression through the pdk1/akt/caspase 3 pathway. Mol. Oncol. 13, 2246-2258. doi: 10.1002/18780261.12553

Pei, Q., Liu, G. S., Li, H. P., Zhang, Y., Xu, X. C., Gao, H., et al. (2019). Long noncoding RNA snhg14 accelerates cell proliferation, migration, invasion and suppresses apoptosis in colorectal cancer cells by targeting mir-944/kras axis through pi3k/akt pathway. Eur. Rev. Med. Pharmacol. Sci. 23, 9871-9881. doi: 10.26355/eurrev_201911_19551
Peng, Y., and Croce, C. M. (2016). The role of micrornas in human cancer. Signal Transduct. Target Ther. 1:15004. doi: 10.1038/sigtrans.2015.4

Poliseno, L., Marranci, A., and Pandolfi, P. P. (2015). Pseudogenes in human cancer. Front. Med. 2:68. doi: 10.3389/fmed.2015.00068

Pu, J., Wei, H., Tan, C., Qin, B., Zhang, Y., Wang, A., et al. (2019). Long noncoding RNA snhg14 facilitates hepatocellular carcinoma progression through regulating mir-4673/socs1. Am. J. Transl. Res. 11, 5897-5904.

Qi, X., Shao, M., Sun, H., Shen, Y., Meng, D., and Huo, W. (2017). Long non-coding rna snhg14 promotes microglia activation by regulating mir-145-5p/pla2g4a in cerebral infarction. Neuroscience 348, 98-106. doi: 10.1016/j.neuroscience.2017. 02.002

Qian, X., Zhao, J., Yeung, P. Y., Zhang, Q. C., and Kwok, C. K. (2019). Revealing lncRNA structures and interactions by sequencing-based approaches. Trends Biochem. Sci. 44, 33-52. doi: 10.1016/j.tibs.2018.09.012

Robidoux, A., Tang, G., Rastogi, P., Geyer, C. E. Jr., Azar, C. A., Atkins, J. N., et al. (2013). Lapatinib as a component of neoadjuvant therapy for her2-positive operable breast cancer (nsabp protocol b-41): an open-label, randomised phase 3 trial. Lancet Oncol. 14, 1183-1192. doi: 10.1016/s1470-2045(13)70411-x

Romero-Barrios, N., Legascue, M. F., Benhamed, M., Ariel, F., and Crespi, M. (2018). Splicing regulation by long noncoding RNAs. Nucleic Acids Res. 46, 2169-2184. doi: 10.1093/nar/gky095

Schmitz, S. U., Grote, P., and Herrmann, B. G. (2016). Mechanisms of long noncoding RNA function in development and disease. Cell. Mol. Life Sci. 73, 2491-2509. doi: 10.1007/s00018-016-2174-5

Shi, C., Zhao, Y., Li, Q., and Li, J. (2021). LncRNA snhg14 plays a role in sepsis-induced acute kidney injury by regulating mir-93. Mediators Inflamm. 2021:5318369. doi: 10.1155/2021/5318369

Simion, V., Haemmig, S., and Feinberg, M. W. (2019). LncRNAs in vascular biology and disease. Vascul. Pharmacol. 114, 145-156. doi: 10.1016/j.vph.2018.01.003

Statello, L., Guo, C. J., Chen, L. L., and Huarte, M. (2021). Gene regulation by long non-coding RNAs and its biological functions. Nat. Rev. Mol. Cell Biol. 22, 96-118. doi: 10.1038/s41580-020-00315-9

Sun, X., Shen, H., Liu, S., Gao, J., and Zhang, S. (2020). Long noncoding RNA snhg14 promotes the aggressiveness of retinoblastoma by sponging microrna124 and thereby upregulating stat3. Int. J. Mol. Med. 45, 1685-1696. doi: 10. 3892/ijmm. 2020.4547

Tang, S. J., and Yang, J. B. (2020). LncRNa snhg14 aggravates invasion and migration as ceRNA via regulating mir-656-3p/sirt5 pathway in hepatocellular carcinoma. Mol. Cell. Biochem. 473, 143-153. doi: 10.1007/s11010-020-03 815-6

Taucher, V., Mangge, H., and Haybaeck, J. (2016). Non-coding RNAs in pancreatic cancer: challenges and opportunities for clinical application. Cell. Oncol. 39, 295-318. doi: 10.1007/s13402-016-0275-7

Tian, D., Sun, S., and Lee, J. T. (2010). The long noncoding RNA, jpx, is a molecular switch for x chromosome inactivation. Cell 143, 390-403. doi: 10.1016/j.cell. 2010.09.049

Tian, Y., Li, L., Lin, G., Wang, Y., Wang, L., Zhao, Q., et al. (2021). IncRNA SNHG14 promotes oncogenesis and immune evasion in diffuse large-B-cell lymphoma by sequestering miR-152-3p. Leukemia Lymphoma 62, 1574-1584. doi: $10.1080 / 10428194.2021 .1876866$

Vincent, A., Herman, J., Schulick, R., Hruban, R. H., and Goggins, M. (2011). Pancreatic cancer. Lancet 378, 607-620. doi: 10.1016/s0140-6736(10)62307-0

$\mathrm{Vu}, \mathrm{T}$., and Claret, F. X. (2012). Trastuzumab: updated mechanisms of action and resistance in breast cancer. Front. Oncol. 2:62. doi: 10.3389/fonc.2012.00062

Wang, J., Su, Z., Lu, S., Fu, W., Liu, Z., Jiang, X., et al. (2018). LncRNA hoxa-as2 and its molecular mechanisms in human cancer. Clin. Chim. Acta 485, 229-233. doi: 10.1016/j.cca.2018.07.004

Wang, J., Zhao, L., Shang, K., Liu, F., Che, J., Li, H., et al. (2020). Long non-coding RNA h19, a novel therapeutic target for pancreatic cancer. Mol. Med. 26:30. doi: 10.1186/s10020-020-00156-4

Wang, Q., Teng, Y., Wang, R., Deng, D., You, Y., Peng, Y., et al. (2018). The long non-coding RNA snhg14 inhibits cell proliferation and invasion and promotes apoptosis by sponging mir-92a-3p in glioma. Oncotarget 9, 12112-12124. doi: 10.18632/oncotarget.23960

Wang, X., Li, W., Chen, Y., and Zhou, L. (2021a). Long non-coding RNA snhg14 affects the proliferation and apoptosis of childhood acute myeloid leukaemia cells by modulating the mir-193b-3p/mcl1 axis. Mol. Med. Rep. 23:90. doi: 10.3892/mmr.2020.11729 
Wang, X., Yang, P., Zhang, D., Lu, M., Zhang, C., and Sun, Y. (2021b). LncRNA snhg14 promotes cell proliferation and invasion in colorectal cancer through modulating mir-519b-3p/ddx5 axis. J. Cancer 12, 4958-4970. doi: 10.7150/jca. 55495

Winkle, M., El-Daly, S. M., Fabbri, M., and Calin, G. A. (2021). Noncoding rna therapeutics - challenges and potential solutions. Nat. Rev. Drug Discov. 20, 629-651. doi: 10.1038/s41573-021-00219-z

Wolff, A. C., Hammond, M. E., Schwartz, J. N., Hagerty, K. L., Allred, D. C., Cote, R. J., et al. (2007). American society of clinical oncology/college of american pathologists guideline recommendations for human epidermal growth factor receptor 2 testing in breast cancer. J. Clin. Oncol. 25, 118-145. doi: 10.1200/jco. 2006.09.2775

Wong, C. M., Tsang, F. H., and Ng, I. O. (2018). Non-coding RNAs in hepatocellular carcinoma: molecular functions and pathological implications. Nat. Rev. Gastroenterol. Hepatol. 15, 137-151. doi: 10.1038/nrgastro.201 7.169

Wu, K., Li, J., Qi, Y., Zhang, C., Zhu, D., Liu, D., et al. (2019). Snhg14 confers gefitinib resistance in non-small cell lung cancer by up-regulating abcb1 via sponging mir-206-3p. Biomed. Pharmacother. 116:108995. doi: 10.1016/j. biopha.2019.108995

Xie, F., Huang, Q., Wang, C., Chen, S., Liu, C., Lin, X., et al. (2020). Downregulation of long noncoding RNA snhg14 suppresses cell proliferation and invasion by regulating ezh2 in pancreatic ductal adenocarcinoma (pdac). Cancer Biomark. 27, 357-364. doi: 10.3233/cbm- 190908

Xu, L., Xu, Y., Yang, M., Li, J., Xu, F., and Chen, B. L. (2020). LncRNA snhg14 regulates the ddp-resistance of non-small cell lung cancer cell through mir133a/hoxb13 pathway. BMC Pulm. Med. 20:266. doi: 10.1186/s12890-02001276-7

Xu, X., Song, F., Jiang, X., Hong, H., Fei, Q., Jin, Z., et al. (2020). Long non-coding RNA snhg14 contributes to the development of hepatocellular carcinoma via sponging mir-217. Onco Targets Ther. 13, 4865-4876. doi: 10.2147/ott.S24 4530

Yang, N., Wang, H., Zhang, L., Lv, J., Niu, Z., Liu, J., et al. (2021). Long non-coding RNA snhg14 aggravates lps-induced acute kidney injury through regulating mir-495-3p/hipk1. Acta Biochim. Biophys. Sin. 53, 719-728. doi: 10.1093/abbs/ gmab034

Yarani, R., Mirza, A. H., Kaur, S., and Pociot, F. (2018). The emerging role of lncRNAs in inflammatory bowel disease. Exp. Mol. Med. 50, 1-14. doi: 10.1038/ s12276-018-0188-9

Ye, T., Zhang, N., Wu, W., Yang, B., Wang, J., Huang, W., et al. (2019). Snhg14 promotes the tumorigenesis and metastasis of colorectal cancer through mir32-5p/skil axis. In Vitro Cell. Dev. Biol. Anim. 55, 812-820. doi: 10.1007/s11626019-00398-5

Zhang, H., Xu, H. B., Kurban, E., and Luo, H. W. (2020). LncRNA snhg14 promotes hepatocellular carcinoma progression via h3k27 acetylation activated pabpc1 by pten signaling. Cell Death Dis. 11:646. doi: 10.1038/s41419-020-02 808-z

Zhang, K., Cai, Y., Zhou, Q., Sun, H., and Wei, J. (2020). Long non-coding RNA snhg14 impedes viability, migration and invasion of endometrial carcinoma cells through modulating mir-93-5p/zbtb7a axis. Cancer Manag. Res. 12, 95159525. doi: 10.2147/cmar.S257419

Zhang, W., Duan, W., Mo, Z., Wang, J., Yang, W., Wu, W., et al. (2020). Upregulation of snhg14 suppresses cell proliferation and metastasis of colorectal cancer by targeting mir-92b-3p. J. Cell. Biochem. 121, 1998-2008. doi: $10.1002 /$ jcb. 29434
Zhang, X., Wang, W., Zhu, W., Dong, J., Cheng, Y., Yin, Z., et al. (2019a). Mechanisms and functions of long non-coding RNAs at multiple regulatory levels. Int. J. Mol. Sci. 20:5573. doi: 10.3390/ijms20225573

Zhang, X., Zhao, P., Wang, C., and Xin, B. (2019b). Snhg14 enhances gemcitabine resistance by sponging mir-101 to stimulate cell autophagy in pancreatic cancer. Biochem. Biophys. Res. Commun. 510, 508-514. doi: 10.1016/j.bbrc.2019. 01.109

Zhang, Y., and Tang, L. (2018). The application of lncRNAs in cancer treatment and diagnosis. Recent Pat. Anticancer Drug Discov. 13, 292-301. doi: 10.2174/ 1574892813666180226121819

Zhang, Y. Y., Li, M., Xu, Y. D., and Shang, J. (2019c). LncRNA snhg14 promotes the development of cervical cancer and predicts poor prognosis. Eur. Rev. Med. Pharmacol. Sci. 23, 3664-3671. doi: 10.26355/eurrev_201905_17790

Zhang, Z., Wang, Y., Zhang, W., Li, J., Liu, W., and Lu, W. (2019d). Long noncoding RNA snhg14 exerts oncogenic functions in non-small cell lung cancer through acting as an mir-340 sponge. Biosci. Rep. 39:BSR20180941. doi: 10. 1042/bsr20180941

Zhao, J. L., Wang, C. L., Liu, Y. L., and Zhang, G. Y. (2019). Long noncoding rna snhg14 enhances migration and invasion of ovarian cancer by upregulating dgcr8. Eur. Rev. Med. Pharmacol. Sci. 23, 10226-10233. doi: 10.26355/eurrev_ 201912_19659

Zhao, L., Liu, Y., Zhang, J., Liu, Y., and Qi, Q. (2019). LncRNA snhg14/mir$5590-3$ p/zeb1 positive feedback loop promoted diffuse large b cell lymphoma progression and immune evasion through regulating pd-1/pd-11 checkpoint. Cell Death Dis. 10:731. doi: 10.1038/s41419-019-1886-5

Zhao, L., Zhang, X., Shi, Y., and Teng, T. (2020). LncRNA snhg14 contributes to the progression of nsclc through mir-206/g6pd pathway. Thorac. Cancer 11, 1202-1210. doi: 10.1111/1759-7714.13374

Zhao, Y. L., and Huang, Y. M. (2019). Lncsnhg14 promotes ovarian cancer by targeting microrna-125a-5p. Eur. Rev. Med. Pharmacol. Sci. 23, 3235-3242. doi: 10.26355/eurrev_201904_17683

Zhong, Y., Yu, C., and Qin, W. (2019). LncRNA snhg14 promotes inflammatory response induced by cerebral ischemia/reperfusion injury through regulating mir-136-5p/rock1. Cancer Gene Ther. 26, 234-247. doi: 10.1038/s41417-0180067-5

Zhu, J., Fu, H., Wu, Y., and Zheng, X. (2013). Function of lncRNAs and approaches to IncRNA-protein interactions. Sci. China Life Sci. 56, 876-885. doi: 10.1007/ s11427-013-4553-6

Conflict of Interest: The authors declare that the research was conducted in the absence of any commercial or financial relationships that could be construed as a potential conflict of interest.

Publisher's Note: All claims expressed in this article are solely those of the authors and do not necessarily represent those of their affiliated organizations, or those of the publisher, the editors and the reviewers. Any product that may be evaluated in this article, or claim that may be made by its manufacturer, is not guaranteed or endorsed by the publisher.

Copyright (C) 2021 Shen, Wang, Zhang, Dong and Xing. This is an open-access article distributed under the terms of the Creative Commons Attribution License (CC BY). The use, distribution or reproduction in other forums is permitted, provided the original author(s) and the copyright owner(s) are credited and that the original publication in this journal is cited, in accordance with accepted academic practice. No use, distribution or reproduction is permitted which does not comply with these terms. 